\title{
AVALIAÇÃO DAS INTERAÇÕES NA APRENDIZAGEM COLABORATIVA CRIATIVA VIA WEB
}

\author{
Interactivity evaluation in creative \\ collaborative learning via Web
}

\section{Deller James Ferreira ${ }^{a}$, Gilberto Lacerda dos Santos ${ }^{\mathrm{b}}$}

\footnotetext{
a Mestre em Sistemas e Informação pelo Instituto Militar de Engenharia - Universidade Federal de Goiás. Goiás, GO - Brasil, e-mail: dellerjames@gmail.com

${ }^{\mathrm{b}}$ Doutor em Educação pela Universite Laval, U.L., Canadá e Doutor em Sociologia pela UnB. Atualmente, é professor e coordenador da Pós-Graduação da Faculdade de Educação da UnB. Brasília, Distrito Federal - Brasil, e-mail: glacerda@unb.br
}

\section{Resumo}

A interatividade na aprendizagem colaborativa na Web é um vasto objeto de estudo de pesquisas recentes em educação. Vários autores inspecionaram transcrições de discussões online com o intuito de investigar a construção do conhecimento colaborativo via Web. Contudo, existem poucas pesquisas que endereçam a construção do conhecimento colaborativo na resolução de problemas que evocam a inovação, que é direcionada para a busca de uma solução criativa. Neste trabalho é proposto um método para análise de processos interativos em função da inovação, criatividade e produção do conhecimento contemplando a teoria dos atos da fala.

Palavras-chave: Criatividade; Aprendizagem colaborativa; Atos da fala; Interatividade. 


\begin{abstract}
The interactivity in collaborative learning in Web is a vast object of study in recent research in education. Many authors have inspected transcriptions of online discussions with the aim to investigate the collaborative knowledge construction via Web. However, there are few researches that address the collaborative knowledge building in solving problem that evokes the innovation and that is directed to the search of a creative solution. In this work is proposed a method to the analysis of interactive processes in function of innovation, creativity, and knowledge production, contemplating the speech acts theory.

Keywords: Creativity; Collaborative learning; Speech acts; Interactivity.
\end{abstract}

\title{
INTRODUÇÃO
}

A crescente difusão das tecnologias de informação oferece novas abordagens para a educação a distância. O meio computacional oferece uma alternativa flexível para a aprendizagem, na qual alunos beneficiam-se de interações significativas, oportunidades para a reflexão e conveniência de aprender a distância. A disponibilidade de ferramentas digitais para o acesso rápido, confiável e barato da informação torna possível a elaboração de novas formas de aprendizagem, baseadas em trocas de mensagens síncronas ou assíncronas em ambientes educacionais na Web.

Práticas educacionais vigentes no Brasil e no exterior refletem uma crescente adoção de ferramentas educacionais para promover a aprendizagem colaborativa na Web. E-mails e fóruns são as ferramentas mais comuns para a troca de mensagens online entre alunos e alunos e professores, sendo a comunicação assíncrona e textual. Comunicações textuais, como meio para intensa troca de mensagens, permitem que todo um episódio colaborativo seja armazenado e reconstruído.

A disponibilidade de protocolos escritos provê um registro fiel das transações de aprendizagem e instrucionais em determinado momento de uma discussão online. Isto torna possível o projeto de metodologias que avaliem a qualidade da aprendizagem, durante um curso ou atividade, correlatas aos produtos que os participantes desenvolveram colaborativamente e aos processos interativos e cognitivos subjacentes às discussões realizadas textualmente.

Rev. Diálogo Educ., Curitiba, v. 8, n. 25, p. 787-800, set./dez. 2008 
Avaliação das interações na aprendizagem colaborativa criativa via $W e b \quad 789$

Metodologias na área de aprendizagem colaborativa na Web são construídas sob tradições de pesquisa como a antropologia, sociologia, linguística e ciência da comunicação, que são devotadas ao entendimento da cultura e da linguagem (STAHL, 2005). Teorias sócio-culturais foram importadas de campos cognatos como base para a aprendizagem colaborativa na $W e b$, sugerindo que a aprendizagem ocorre a nível individual e social. Vygotsky (1978) é a maior influência nesta área. Este autor elaborou uma teoria sócio-cultural na qual a experiência social da linguagem é vista como maior fator de influência cognitiva.

O desenvolvimento da razão tem sido um importante objetivo educacional. Embora a psicologia tradicional tenha descrito a racionalidade em termos de regras lógicas, um número de argumentos da psicologia cognitiva atual aponta para a necessidade de vislumbrá-la como uma prática social (RESNICK; LEVINE; HIGGINS, 1993). Para Vygotsky (1978) toda função mental superior se dá a nível externo antes de ser interiorizada.

$\mathrm{Na}$ aprendizagem colaborativa via $W e b$, o foco é a racionalidade verbal descrita em uma representação textual digital. A aprendizagem colaborativa na Web é caracterizada como dialógica (SCHIRE, 2006) e o entendimento do discurso eletrônico, nas suas dimensões cognitiva e interativa, é central para o desenvolvimento de processos de mediações instrucionais à distância.

A mudança conceitual e obtenção de um conhecimento mais aprofundado e partilhado são objetivos educacionais na solução de problemas conjuntos. É esperado que alunos construam significados relacionais de modo incremental por meio de interações. Tais objetivos podem ser melhor alcançados quando alunos engajam-se em diálogos racionais e intencionais, baseados em discussões democráticas. O discurso é transformativo, sendo o meio pelo qual o conhecimento é racionalmente transformado, criticado e partilhado.

Vários pesquisadores investigaram o processo dialógico de construção do conhecimento colaborativo via Web (RATTLEF, 2007; BEREITER e SACARDAMALIA, 2003; GUNAWARDENA; LOWE; ANDERSON, 1997; DE WEVER; SCHELLENS; KEER, 2006; STAHL, 2005). Em geral, suas pesquisas proveem subsídios para a análise de informações que não se situam a nível superficial do discurso virtual, provendo evidências convincentes acerca da aprendizagem e construção do conhecimento ao longo do processo colaborativo. Contudo, poucos autores incorporam a criatividade a modelos dialógicos.

A interação subjacente à conversação é, geralmente, vislumbrada como uma forma dos alunos construírem colaborativamente aproximações sofisticadas de conceitos científicos, por meio de um refinamento gradual de significados parciais e ambíguos (ROCHELLE, 1992). O consenso entre os alunos em colaboração é buscado pelo exame e esclarecimento de pontos de conflito ou aspectos duvidosos em função de sua validade e veracidade. Neste caso, os alunos estão construindo um conhecimento já estabelecido culturalmente ou resolvendo um problema cujas

Rev. Diálogo Educ., Curitiba, v. 8, n. 25, p. 787-800, set./dez. 2008 
possíveis soluções, incluindo sua solução ótima, são conhecidas. Assim sendo, a análise das interações entre os alunos pode ser realizada com base em resultados culturalmente estabelecidos e previamente conhecidos pelo professor.

Há uma necessidade de se expandir as formas de análise de discursos digitais no sentido de abarcar a solução de problemas inéditos. A educação nesse sentido visa a inovação, onde soluções não são previamente conhecidas. Deste modo o diálogo deve incorporar e explicitar a criatividade verbal aliada a racionalidade, possuindo uma natureza exploratória além de crítica, sendo que pode haver mais de uma solução correta com diferentes critérios de avaliação. Critérios estes a serem usados na tomada de decisão na escolha da melhor solução. Além da busca de um conhecimento mais profundo é almejada a originalidade.

Neste trabalho é proposta uma metodologia para a análise de aspectos interativos e cognitivos que emergem em diálogos via $W e b$, entre alunos que se propõem a construir o conhecimento colaborativamente com o intuito de obter soluções criativas para uma classe de problemas correlatos a educação para a inovação.

\section{MATERIAL E MÉTODOS}

Bereiter e Scardamalia (2003) definem a construção do conhecimento como uma tentativa de melhoria do conhecimento, considerando idéias em respeito a seus pontos fortes, fracos, aplicações, limitações e potencial para desenvolvimento posterior. Em ambientes computacionais para a construção do conhecimento, alunos abordam problemas sob múltiplas perspectivas, engajam-se em um discurso para reconstruir suas idéias e trabalham colaborativamente para o avanço do conhecimento. O conceito de construção do conhecimento refere-se ao esforço coletivo para ao avanço e elaboração de artefatos conceituais.

O conhecimento é articulado e interpretado ao invés de assimilado por transmissão, em um processo que requer que o aluno trabalhe no limite de sua competência intelectual e progressivamente busque se superar, almejando cada vez mais altos padrões de performance.

Embora o discurso não seja a única forma de construção do conhecimento, o mesmo é central para o processo de construção do conhecimento. A aprendizagem é um processo interativo onde alunos adquirem habilidades comunicativas e desenvolvem suas habilidades mentais dialogicamente, seguindo regras de um diálogo democrático e com o intuito de resolver problemas.

Por meio do discurso os alunos identificam suas próprias idéias e as comparam e contrastam com as de outros alunos. Os mesmos perseguem o propósito de superar continuamente seus resultados e os resultados de outros alunos e se comprometem a partilhar o conhecimento pela racionalidade e não acatar idéias pelo conformismo.

Rev. Diálogo Educ., Curitiba, v. 8, n. 25, p. 787-800, set./dez. 2008 
Avaliação das interações na aprendizagem colaborativa criativa via Web 791

O termo aprendizagem na aprendizagem colaborativa, usualmente, se refere a processos cognitivos relacionados ao entendimento e à aquisição do conhecimento do indivíduo. Contudo, existem trabalhos em que o aspecto colaborativo amplia o conceito de aprendizagem para a interação grupal. Stahl considera a existência de um conhecimento grupal, que não pode estar em nenhuma mente individual, mas que é, interativamente, obtido pelo grupo e pode persistir em artefatos físicos ou simbólicos (STAHL, 2005).

O conhecimento grupal não pode ser considerado como um tipo de média entre os componentes do grupo, não é, meramente, um acordo sobre conhecimentos prévios, nem tampouco uma sobreposição de conhecimentos individuais. O conhecimento grupal é construído por meio das interações dos membros individuais do grupo, não somente pela soma dos esforços dos indivíduos. É uma propriedade emergente do discurso e interação, a qual não é, necessariamente, reduzível às opiniões e entendimento dos indivíduos.

Alunos em colaboração resolvem problemas baseados em um conhecimento partilhado, havendo, concomitantemente, as perspectivas individual e grupal. Neste caso, tanto os processos de construção individual quanto os processos de construção grupal são levados em consideração. A construção conjunta do grupo e a aquisição individual do conhecimento são entendidos como dois conceitos distintos (DILLEMBOURG, 1999). Desse modo, fica clara a importância dada aos processos que geram e transformam o conhecimento considerando ambos os pontos de vista, individual e social, tendo-se sempre como pano de fundo suas inter-relações.

Neste trabalho enfocamos a construção do conhecimento aliada à criatividade. São considerados problemas com diferentes soluções plausíveis e desconhecidas. Enquanto os alunos possuem o comprometimento de resolver problemas de modo a ir além conhecimentos e entendimentos pré-existentes. $\mathrm{O}$ discurso digital deve ser examinado por meio da investigação de processos colaborativos, onde um conhecimento novo é desenvolvido por meio do diálogo. Tendo em vista que o foco principal não é a transmissão de conhecimento cultural de uma geração a outra, mas sim a produção do conhecimento. Para alcançar este objetivo buscamos fundamentação no modelo de análise de interações de Gunawardena (1997), nas habilidades cognitivas relativas a criatividade propostas por Guilford (1984) e embasamento nos atos da fala (HABERMAS, 1997; AUSTIN, 1962; SEARLE, 1979; HYMES, 1974).

Rev. Diálogo Educ., Curitiba, v. 8, n. 25, p. 787-800, set./dez. 2008 


\section{Modelo de análise de interações em ambientes colaborativos}

O modelo de análise de interação Gunawardena (1997) é utilizado neste trabalho como ponto de partida para a investigação da construção social do conhecimento em ambientes assíncronos de comunicação no computador. Neste modelo, os alunos se engajam em cinco fases de produção conjunta do conhecimento.

1. Fase de compartilhamento e comparação da informação. Referente ao acesso da mesma referência bibliográfica ou banco de dados, intersubjetividade na interpretação literal, gerenciamento de grande quantidade de informações e seleção de informação relevante. Relativa a descrição da origem, contexto, definição, intenção e propósito de uma questão e a colocação de novas questões. Colocação de um fato, conceito ou teoria. Explicação de uma opinião, esclarecimento de um desentendimento ou o não entendimento de um conceito;

2. Fase de descoberta e exploração de inconsistência entre idéias. Nesta fase, se há uma contradição, o aluno deve colocar uma opinião ou evidência substituta ou diferente. Há também defesa de declaração anterior com uma evidência ou interpretação posterior, verificação de uma hipótese ou opinião alheia, realização de avaliação ou julgamento sobre um ponto de vista, conclusões amplas deduzidas a partir de interpretações prévias e sugestões de modificações de planos de ação;

3. Fase de negociação do significado e co-construção do conhecimento. Tentativa de chegar-se a um acordo ou entendimento consistente sobre um assunto ou solução de um problema. Relacionada às ações de refinar, revisar e melhorar uma idéia de forma conjunta. Organização e integração de idéias diferentes, generalização ou resumo e estabelecimento de uma conclusão consistente;

4. Fase de teste e modificação do conhecimento gerado na fase anterior. Fase relacionada à reflexão acerca da estratégia de resolução de problemas utilizada;

5. Fase de aquiescência e aplicação do conhecimento construído. Referente à criação de uma regra geral e aplicação a um contexto novo, busca da intersubjetividade da solução, avaliação do grupo e realização de comparações com outras abordagens.

Rev. Diálogo Educ., Curitiba, v. 8, n. 25, p. 787-800, set./dez. 2008 
Avaliação das interações na aprendizagem colaborativa criativa via $W e b \quad 793$

O modelo descrito anteriormente considera, além de processos interativos, processos cognitivos subjacentes. Contudo, sem endereçar diretamente habilidades cognitivas relacionadas à criatividade.

A construção criativa do conhecimento é, fundamentalmente, um processo social por natureza. Inovações são co-construções que surgem a partir de relações inter-pessoais Este processo pressupõe altas competências cognitivas dos participantes (PAAVOLA; HAKKARAINEN, 2005). Deste modo, do ponto de vista de criação do conhecimento, além do pensamento crítico, lógico e avaliativo, devemos vislumbrar outros processos mentais relativos a processos de descoberta.

\section{Habilidades cognitivas relacionadas à criatividade} cognitivas como:

$\mathrm{Na}$ concepção criativa de problemas, alunos evocam habilidades

- reconhecer padrões, porque usualmente caos e complexidade são causados por padrões simples, que quando reconhecidos levam à solução do problema;

- ver de outros modos, que significa procurar por padrões a partir de diferentes perspectivas: lógica, organizacional, procedimental, experimental, holística, especulativa, etc.

- fazer conexões, idéias criativas são o resultado da sinergia que ocorre entre pensamentos;

- tirar vantagem de uma chance, o que significa calcular riscos, deste modo tira-se proveito de uma oportunidade que pode permitir caminhar na direção de uma solução criativa.

Visualizando a criatividade sob a perspectiva de tarefas relacionadas à solução de problemas uma variedade de habilidades caracteriza o processo criativo. De acordo com Guilford (1984), há quatro habilidades principais, que são fluência, flexibilidade, originalidade e elaboração.

A fluência é a produção de múltiplas definições para um problema, alternativas, idéias ou soluções. A probabilidade de se achar uma idéia frutífera aumenta de acordo com o número de idéias geradas. Os alunos direcionam seus pensamentos na geração de idéias não convencionais.

Flexibilidade é a habilidade de processar idéias de diferentes formas dado um mesmo objeto, imagem ou símbolo. É a habilidade de abandonar velhas formas de pensar e iniciar distintas direções. A flexibilidade é adaptativa quando

Rev. Diálogo Educ., Curitiba, v. 8, n. 25, p. 787-800, set./dez. 2008 
é objetivada a solução de um problema específico, desafio ou dilema, sendo especialmente importante quando métodos lógicos não proporcionam resultados satisfatórios. O pensamento flexível evoca, por exemplo, mudanças conceituais, contradições, diferentes pontos de vista, planos alternativos, abordagens diversas e diferentes perspectivas de uma mesma situação.

A originalidade significa fugir do óbvio e lugar comum ou romper com velhas formas de pensar. Idéias originais são usualmente descritas como únicas, surpreendentes, revolucionárias e não convencionas. As analogias e as metáforas estão relacionadas à originalidade, podendo ser usadas para sugerir comparações que ofereçam soluções.

A elaboração é o refinamento de uma idéia, é o que os pesquisadores usualmente chamam de "amadurecer uma idéia". Uma idéia é transformada em uma idéia mais complexa, enriquecida por detalhes.

\section{Atos da fala}

A teoria da ação comunicativa de Habermas é fundamental para o entendimento da construção do conhecimento que emerge da interação em ambientes colaborativos na Web. Habermas (1997) postulou que o conceito da comunicação racional é baseado na experiência advinda da força irrestrita, unificadora e consensual da fala argumentativa, na qual participantes sobrepujam suas visões subjetivas. Para Habermas, uma comunicação compreensiva, confiável e apropriada é o que implica em um entendimento mútuo entre as pessoas.

Na teoria da ação comunicativa de Habermas (1997), o discurso é situado em um contexto social onde são subjacentes normas de comunicação. Contudo, estas normas devem obedecer a um ideal democrático. Participantes em um discurso social possuem oportunidades iguais para iniciar e sustentar a comunicação. Todas as formas de coerção devem ser eliminadas para que haja uma redefinição conjunta de regras que permitam a todos dialogarem a partir de bons argumentos. Em outras palavras, regras devem ser redefinidas de maneira racional, tornando a comunicação um sistema democrático de trocas. Este autor advoga a favor de uma situação ideal de comunicação, na qual a comunicação é democrática, havendo oportunidades iguais para atores sociais se comunicarem de modo não distorcido.

A comunicação, orientada por um objetivo onde a mensagem possui uma intenção subjacente e a racionalidade do discurso proposta por Habermas são a base para a teoria dos atos da fala. $\mathrm{Na}$ teoria dos atos da fala proposta por Austin (1962) e Searle (1979), atos da fala relacionam mensagens em sequências de discussão. A noção de atos da fala foi desenvolvida a partir da observação de Austin de que nem todas as sentenças são simplesmente a colocação de fatos, algumas são

Rev. Diálogo Educ., Curitiba, v. 8, n. 25, p. 787-800, set./dez. 2008 
Avaliação das interações na aprendizagem colaborativa criativa via Web 795

performativas. Austin definiu uma sentença como sendo performativa quando em uma sentença ou parte dela está sendo executada uma ação. De acordo com Searle é executado um ato da fala quando ao dizer-se algo é executada uma ação. Para Searle o ato da fala é a unidade linguística básica de comunicação e significado e esses atos produzem consequências entre os participantes de um discurso.

No presente trabalho também evocamos o trabalho de Hymes (1974). Hymes identificou formas nas quais a linguagem é determinada culturalmente. Para este autor, a linguagem é constituída por atos sociais, sendo um produto cultural e uma ferramenta para membros de um grupo se comunicarem. Hymes propõe ir-se além dos atos da fala, unidade de análise, definindo uma hierarquia aninhada de unidades de análise chamada por ele: situação da fala ou situação comunicativa, evento comunicativo e ato comunicativo. Nesta hierarquia atos comunicativos fazem parte de eventos comunicativos, que por sua vez estão contidos em situações comunicativas. A situação comunicativa é o contexto no qual a comunicação ocorre.

\section{RESULTADOS}

Com base no referencial teórico abordado anteriormente é proposto um modelo original de análise dos processos interativos em função da inovação, criatividade e produção do conhecimento, com o propósito de prover mais subsídios ao entendimento de processos individuais e suas características interativas. Temos como característica fundamental deste modelo a interação entre os alunos vista como atos comunicativos circunscritos em eventos contidos em uma situação educacional. As interações são mediadas pela tecnologia e pela linguagem. A mediação tecnológica provê uma base persistente e compartilhada de representações permitindo, deste modo, que o conhecimento colaborativo seja construído e que reflexões acerca de sua criação sejam elaboradas, enquanto que a linguagem é o meio para que entendimento mútuo seja obtido e para que o pensamento racional seja expresso.

Como instanciação do conceito de situação ideal de Habermas, formulamos o modelo como condições para uma situação ideal de aprendizagem. Descartamos, como Habermas, a coesão e qualquer forma de ideologia, exceto a força do bom argumento, o qual possui como pano de fundo o compromisso dos alunos com o avanço e criação do conhecimento. A avaliação do professor não ocorre em função de uma solução ótima, sendo sua análise processual. As discussões não são centradas na verdade, mas sim nos processos subjacentes a sua obtenção. Processos estes considerados sob uma ótica de crítica livre, objetividade e racionalidade individuais imersos nas matrizes histórico-culturais do aluno e englobados pela situação colaborativa proposta pelo professor.

Rev. Diálogo Educ., Curitiba, v. 8, n. 25, p. 787-800, set./dez. 2008 
Como uma forma de melhor entender os processos interativos da aprendizagem colaborativa na $W e b$ propomos uma extensão das idéias providas anteriormente sobre aprendizagem colaborativa pela teoria dos atos da fala. A teoria dos atos da fala (HABERMAS, 1997; HYMES, 1974; SEARLE, 1979; AUSTIN, 1962) fornece um meio de sistematização para as mensagens online a serem avaliadas e devidamente embasadas teoricamente. Esta sistematização provê uma base para o desenvolvimento de categorias de análise e sua fundamentação alia-se de modo consistente as idéias sobre aprendizagem colaborativa adotadas neste trabalho.

O modelo proposto é um refinamento das fases de colaboração propostas por Gunawardena, no sentido de acoplar e destacar atos comunicativos individuais e suas características interativas, ambos referentes ao processo criativo conjunto. De acordo com a divisão de uma situação comunicativa por eventos e ações, realizada por Hymes, tais atos comunicativos são parte integrante de eventos (fases do modelo de Gunawardena), que, por sua vez, integram uma situação de aprendizagem. Deste modo, o professor possui um instrumento a nível individual e grupal para realizar suas avaliações sobre o processo de aprendizagem situado na resolução de um problema.

A seguir serão descritos os atos comunicativos que propiciam uma análise do processo de criação do conhecimento colaborativo a nível individual:

1. erificação da veracidade: constatação de que dado fato é verdadeiro ou falso ou de que dado estado existe;

2. Decisão: decisão acerca de qual fato $\mathrm{X}$ ou $\mathrm{Y}$ é verdadeira. Conclusões a partir de hipóteses. Estabelecimento de critérios;

3. Formação de conceito: abstrações a partir de feições, estados e correlações de entidades;

4. Especificação de feição: definição das propriedades de uma entidade;

5. Quantificação: estabelecimento ou estimativa de frequência, percentagem e quantidades em geral;

6. Definição: gerar o significado de um conceito;

7. Comparação: metáforas, analogias e comparações diversas de acordo com determinados critérios;

8. Interpretação: conceito ou afirmação inferida de um padrão de dados estático ou dinâmico. Chegando-se a conclusões primárias ou finais;

9. Dedução: antecedente ou consequente lógico. Identificação de instâncias de regras;

10.Instrumentalização: montagem de plano, fonte, objeto ou procedimento que permite que objetivos sejam alcançados;

11. Checagem da Informação: avaliação de fontes e qualidade da informação;

Rev. Diálogo Educ., Curitiba, v. 8, n. 25, p. 787-800, set./dez. 2008 
Avaliação das interações na aprendizagem colaborativa criativa via Web 797

12. Avaliação da consistência: exame de pensamento na busca por contradições;

13. Re-direcionamento: reorientação, transformação e redefinição conceitual.

14. Especulação: abdução;

15. Análise da relevância: identificação de elementos, propriedades e relações relevantes de acordo com critérios de relevância;

16. Consideração de diferentes pontos de vista: ver idéias e objetos de distintos pontos de vista. Diferentes contextos;

17. Produção fluente: produção de idéias múltiplas, alternativa e soluções;

18. Produção original: extrapolação;

19. Elaboração: aprofundamento do conhecimento. Detalhamento. Complexidade de inter-relações internas. Análise. Síntese;

20. Integração: combinação e integralização de idéias. Síntese;

21. Organização Convergente: constatação de pertinência a uma classe. Associações. Caminho delineado e seguido;

22. Organiz̧ação Divergente: constatação de exclusão a uma classe. Vários caminhos delineados;

23. Indução: procura de padrões ou regularidades.

Em seguida serão descritos os atos comunicativos, que permitem uma análise do processo de criação do conhecimento colaborativo a nível grupal, refletindo as feições interativas de atos individuais:

1. Explicação: fundamentar uma opinião. Esclarecer um desentendimento ou conceito difuso. Compartilhar informação;

2. Defesa: defender afirmação anterior com evidência ou interpretação posterior;

3. Ataque: avaliar hipótese ou opinião alheia;

4. Desafio: desafiar outros para engajarem-se na discussão grupal;

5. Inconsistência: inconsistência de idéias, conceitos ou afirmações;

6. Discordancia: identificando áreas de desentendimento na busca de um plano de ação;

7. Questões: perguntando e respondendo no sentido de avaliar a extensão do desentendimento;

8. Avanço: mudança de posição dos participantes e avanço dos argumentos e considerações;

9. Co-construção do conhecimento: integração do conhecimento. Síntese conjunta. Obtenção de um "conhecimento grupal";

10. Reflexão conjunta: acomodação de metáforas e analogias;

Rev. Diálogo Educ., Curitiba, v. 8, n. 25, p. 787-800, set./dez. 2008 
11. Teste: teste e modificação da co-construção obtida em confronto com informações dados coletados ou experiências pessoais;

12. Aplicação: aplicação do novo conhecimento;

13. Meta-cognição: reflexão acerca do processo de produção do conhecimento;

14. Intersubjetividade: intersubjetividade da solução, garantindo que todos integrantes partilhem a solução.

O professor deve estabelecer uma situação de aprendizagem contextualizada que promova a passagem dos alunos pelos eventos propostos. Tal situação deve ter como referência a situação ideal do modelo. Contudo, pode haver uma dinâmica situacional, na qual a sequência dos eventos não seja rigorosamente seguida.

\section{CONSIDERAÇÕES FINAIS}

O presente trabalho se aplica a ferramentas textuais de comunicação assíncronas como os fóruns de discussão. Tais ferramentas fornecem um suporte computacional para a argumentação a nível de troca de mensagens textuais, geralmente, encadeadas em ordem cronológica.

Alunos resolvendo problemas colaborativamente via Web são mediados por artefatos digitais que permitem a articulação de uma base de conhecimento. O professor, na busca de um processo de facilitação da construção colaborativa do conhecimento, por meio de mensagens eletrônicas, pode utilizar o método proposto neste trabalho para avaliar o processo colaborativo criativo.

O método apresentado aqui proporciona um modelo para análise de interações em grupos pequenos, em média com quatro alunos. No modelo, é apresentada uma situação ideal de aprendizagem, na qual o conhecimento deve ser progressivamente transformado e aprofundado. Tal situação é dividida em eventos detalhados em atos comunicativos que contemplam aspectos relativos a uma boa argumentação no sentido de abarcar processos cognitivos relevantes para o raciocínio critico e para a criatividade, bem como englobar suas características iterativas. Deste modo permitindo que o professor realize uma análise tanto a nível individual quanto grupal, bem como a nível situacional de eventos e ações comunicativas.

O modelo formulado neste trabalho é de crucial importância para uma avaliação do processo de aprendizagem colaborativo via Web, pois é um parâmetro para caracterizar uma aprendizagem colaborativa efetiva. Sem um modelo teórico, que descreva processos de construção do conhecimento colaborativa, não é possível identificar indicadores empíricos com base em um instrumento de codificação.

Rev. Diálogo Educ., Curitiba, v. 8, n. 25, p. 787-800, set./dez. 2008 
Avaliação das interações na aprendizagem colaborativa criativa via Web 799

A razão e a aprendizagem estão sob o prisma do diálogo, refletindo o processo de construção colaborativa do conhecimento. Atos comunicativos são utilizados como mecanismos de interação social que esmiúçam o processo de aprendizagem colaborativa. Portanto, a análise dos atos comunicativos envolvidos no processo colaborativo é um caminho promissor na obtenção de seu entendimento.

\section{REFERÊNCIAS}

AUSTIN, J. L. How to do things with words. Cambridge: O. Urmson and Marina Sbisà, 1962.

BEREITER, C.; SCARDAMALIA, M. Learning to work creatively with knowledge. In: DE CORTE, E. et al. (Ed.). Unravelling basic components and dimensions of powerful learning environments. EARLI advances in learning and instruction series. North-Holland: Elsevier, 2003. p. 15.

WEVER, B. de; SCHELLENS, T.; KEER, V. Content analysis schemes to analyze transcripts of online asynchonous discussion groups: a review. Computers and Education, v. 46, n. 1, p. 6-28, 2006.

DILLEMBOURG, P. Introduction: what do you mean by collaborative learning? In: DILLEMBOURG, P. (Ed.). Collaborative learning: cognitive and computational approaches. Amsterdam: Pergamon, 1999. p. 1-19.

GUILFORD, J. P. Varieties of divergent-production abilities or functions. Journal of Creative Behavior, v. 18, n. 1, p. 1-10, 1984.

GUNAWARDENA, C.; LOWE, C.; ANDERSON, T. Analysis of a global online debate and the development of an interaction analysis model for examining social construction of knowledge in computer conferencing. Journal of Educational Computing Research, v. 17, n. 4, p. 395-429, 1997.

HABERMAS, J. Teoria de la accion comunicativa: complementos y estudios prévios. Madrid: Cátedra, 1997.

HYMES, D. Foundations in sociolinguistics an ethnographic approach. Philadelphia: The University of Pensylvania Press Inc., 1974.

PAAVOLA, S.; HAKKARAINEN, K. The knowledge creation metaphor. Science and Education, v. 14, n. 6, p. 234-255, 2005.

Rev. Diálogo Educ., Curitiba, v. 8, n. 25, p. 787-800, set./dez. 2008 
RATTLEFF, P. The reliability of content analysis of computer conference communication. Computers and Education, v. 49, n. 2, p. 230-242, 2007.

RESNICK, L.; LEVINE, J.; HIGGINS, T. Social foundations of cognition. Annual Review Psychology, v. 44, p. 585-612, 1993.

ROSCHELLE, J. Learning by collaborating: convergent conceptual change. Journal of the Learning Sciences, v. 2, n. 3, p. 235-276, 1992.

SCHIRE, S. Knowledge building in asynchronous discussion groups: going beyond quantitative analysis. Computers and Education, v. 46, n. 1, p. 49-70, 2006.

SEARLE, J. Expression and meaning. Cambridge: Cambridge University Press, 1979.

STAHL, G. Group cognition in computer assisted collaborative learning. Journal of Computer Assisted Learning, v. 21, n. 2, p. 79 90, 2005.

VYGOTSKY, L. Mind in society. Cambridge: Harvard University Press, 1978.

Recebido: 27/03/2008

Received: $03 / 27 / 2008$

Aprovado: 01/07/2008

Approved: 07/01/2008

Rev. Diálogo Educ., Curitiba, v. 8, n. 25, p. 787-800, set./dez. 2008 